\title{
Correction to: Legal Ramifications of Blockchain Technology
}

\author{
Akinyemi Omololu Akinrotimi
}

\section{Correction to:}

Chapter "Legal Ramifications of Blockchain Technology" in: M. A. Khan et al. (eds.), Decentralised Internet of Things, Studies in Big Data 71, https://doi.org/10.1007/978-3-030-38677-1_10

In the original version of the book, the following belated correction has been incorporated: The order of the author's name has been changed from Akinrotimi Akinyemi Omololu to Akinyemi Omololu Akinrotimi in chapter "Legal Ramifications of Blockchain Technology". The chapter and book have been updated with the changes. 